\title{
Availability of integrated family planning services in HIV care and support sites in sub-Saharan Africa: a secondary analysis of national health facility surveys
}

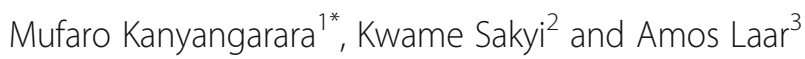

\begin{abstract}
Background: Integrating family planning (FP) with HIV care and treatment programs is a strategy to expand FP service delivery and prevent unintended pregnancies among women living with HIV. However, little is known about the extent to which FP services are available in health facilities providing HIV services across sub-Saharan Africa. In this study, we assessed the availability of integrated FP services and the associated factors in HIV care and support sites across sub-Saharan Africa.

Methods: We conducted a secondary analysis of nationally representative facility-level data from Service Availability and Readiness Assessments (SARA) and Service Provision Assessments (SPA) conducted in 10 sub-Saharan African countries between 2012 and 2015. We used six indicators that reflect the structure and process of care essential for FP service delivery in HIV care and support facilities to define the outcome of interest - onsite availability of integrated FP services. Multivariate logistic regression was used to explore facility-level characteristics associated with the outcome.

Results: Among the 3161 health facilities offering HIV care and support services, most reported also offering FP services at the same location. The availability of three FP methods was higher than the availability of FP guidelines and trained staff. Onsite availability of integrated FP services ranged from 10 to $61 \%$. Results of multivariate logistic regression indicated that the odds of having onsite integrated FP services available was higher in HIV care and support sites that were operated by the government, classified as a tertiary level care facility, and provided services for PMTCT, antenatal care and basic surgery.

Conclusions: Our findings indicate critical shortcomings in the preparedness of HIV care and support sites to deliver onsite integrated FP services. Renewed efforts are needed to address these supply-side barriers and ensure that integrated FP and HIV services meet the unique needs of HIV clients.
\end{abstract}

Keywords: HIV, Family planning, Sub-Saharan Africa, Health facility surveys

\footnotetext{
* Correspondence: mkanyan1@jhu.edu

'Department of International Health, Johns Hopkins Bloomberg School of

Public Health, 615 N. Wolfe Street, Baltimore, MD, USA

Full list of author information is available at the end of the article
}

(c) The Author(s). 2019 Open Access This article is distributed under the terms of the Creative Commons Attribution 4.0 International License (http://creativecommons.org/licenses/by/4.0/), which permits unrestricted use, distribution, and reproduction in any medium, provided you give appropriate credit to the original author(s) and the source, provide a link to the Creative Commons license, and indicate if changes were made. The Creative Commons Public Domain Dedication waiver (http://creativecommons.org/publicdomain/zero/1.0/) applies to the data made available in this article, unless otherwise stated. 


\section{Background}

Since the start of the HIV epidemic, an estimated 78 million people have acquired HIV, and 35 million have died of AIDS-related causes [1]. In 2016, there were 36.7 million people living with HIV/AIDS worldwide, with 25.5 million residing in Sub-Saharan Africa. Annually about 2.1 million people become newly infected with HIV, including 150,000 children ( $<15$ years), most of whom acquire the infection vertically from their mothers, during pregnancy, childbirth or breastfeeding $[1,2]$.

The scale-up of interventions for the prevention of mother-to-child transmission of HIV (PMTCT) and antiretroviral treatment for eligible pregnant women and children has led to significant reductions in HIV transmission, morbidity and mortality [3]. The benefits associated with improved access to antiretroviral therapy (ART) may be offset by high rates of unintended pregnancies and low levels of contraceptive use among women living with HIV in sub-Saharan Africa [4-8]. Preventing unintended pregnancies in HIV-infected women is recognized an essential component of a comprehensive response to HIV/AIDS, especially the global PMTCT $[9,10]$. The integration of family planning (FP) services into HIV/AIDS care and treatment programs is an effective approach to simultaneously reducing vertical transmission of HIV, increasing access to contraception, and reducing maternal deaths [11-13]. Furthermore, at a health systems level, the delivery of FP services as part of the HIV continuum of care can lead to improvements in access to essential health services, efficiency of limited resources and clinical practice [14-16]. Models to integrate HIV and FP service delivery range from the provision of comprehensive FP services from the same HIV service provider to referral-based approaches [17]. The effectiveness of a particular model of integration depends on contextual factors such as the burden of HIV and unique FP needs, health system factors such as the commodity supply chain, provider level factors such as competence and attitude that influence the quality of care, and structural factors such as infrastructure, equipment and commodities [18-21]. Deficiencies in structural inputs can hinder the delivery of integrated services resulting in missed opportunities to address unmet needs. Evaluating the availability of structural inputs and processes of care necessary for integrated service delivery can help identify barriers to the implementation of integrated FP and HIV services.

Many studies have examined the integration of FP services with HIV programs in one or more health facilities in a single country [14, 22-25]. However, few studies have examined the integration of FP services at a national-level or across multiple countries systematically $[20,21]$. Consequently, differences in the availability of integrated FP services in HIV programs across multiple countries have been underexplored. The current study aimed to assess the on-site availability of FP services at HIV care and support sites in 10 sub-Saharan African countries. We also evaluated facility-level factors associated with onsite availability of integrated FP services. Findings from this multi-country analysis reveal critical shortcomings in the implementation of integrated FP and HIV service delivery, and provide evidence to guide the implementation of effective integrated FP and HIV services at scale.

\section{Methods}

\section{Data sources}

Data were obtained from the Service Provision Assessments (SPA) and Service Availability and Readiness Assessments (SARA) [26, 27]. The SPA and SARA are nationally representative, cross-sectional facility-based surveys that collect comprehensive information on the availability and functionality of health systems in the provision of essential health services, including antenatal care, obstetric care, HIV/AIDS care and treatment, and FP. Both surveys include a facility checklist administered to the facility in-charge. The availability of basic amenities, equipment, diagnostics, medicines and commodities for the provision of health services is directly observed and verified by the interviewer. Further details about the survey design and sampling strategy can be found in final survey reports $[26,27]$.

\section{Study setting}

Our analysis included available data from SPAs and SARAs conducted between 2012 and 2015 in 10 sub-Saharan African countries: Benin, Burkina Faso, Democratic Republic of Congo (DRC), Malawi, Senegal, Sierra Leone, Tanzania, Togo, Uganda, and Zimbabwe. The included countries represent a diversity of populations with a range of sexual and reproductive health needs, and settings with varying nature of the HIV epidemic (Table 1). Overall, contraceptive prevalence rate ranges from $16.2 \%$ in Burkina Faso to $66.8 \%$ in Zimbabwe, and unmet need for FP ranges from $10.4 \%$ in Zimbabwe to $34.3 \%$ in Uganda. Coverage of antenatal care (ANC) and facility deliveries is substantial, with between 34 and $76 \%$ of pregnant women attending at least four ANC visits, and between 54 and $91 \%$ of pregnant women delivering in a health facility. The incidence rate of HIV ranges from 0.08 to 3.03 per 1000 person-years. The burden of HIV and coverage of HIV interventions tends to be higher in countries in the Southern and Eastern Africa regions like Tanzania and Zimbabwe, compared to countries in the Western and Central African regions like the Togo and Sierra Leone. National health expenditures per capita for 2015 ranged from US\$20 to US $\$ 170$. 
Table 1 State of sexual and reproductive health and the HIV epidemic in 10 sub-Saharan African countries, 2012-2015

\begin{tabular}{|c|c|c|c|c|c|c|c|c|c|c|}
\hline & $\begin{array}{l}\text { Health expenditure per } \\
\text { capita in } U S^{\text {ba }}\end{array}$ & $\begin{array}{l}\text { People living } \\
\text { with } \mathrm{HIV}^{\mathrm{b}}\end{array}$ & $\begin{array}{l}\text { HIV } \\
\text { incidence § }\end{array}$ & $\begin{array}{l}\text { ART } \\
(\%)^{b}\end{array}$ & $\mathrm{PMTCT}^{\mathrm{b}}$ & ANC4+ (\%) & $\begin{array}{l}\text { Facility } \\
\text { deliveries }(\%)^{c}\end{array}$ & $\mathrm{TFR}^{\mathrm{C}}$ & $\begin{array}{l}\text { Unmet need } \\
\text { for } \mathrm{FP}^{\mathrm{C}}\end{array}$ & $\begin{array}{l}\text { CPR } \\
(\%)^{d}\end{array}$ \\
\hline Benin & 31 & 67,000 & 0.34 & 57 & $>95$ & 59 & 87 & 4.9 & 32.6 & 17.9 \\
\hline $\begin{array}{l}\text { Burkina } \\
\text { Faso }\end{array}$ & 33 & 95,000 & 0.19 & 60 & 83 & 34 & 66 & 6.0 & 24.5 & 16.2 \\
\hline DRC & 20 & 370,000 & 0.17 & 42 & 70 & 48 & 80 & 6.6 & 27.7 & 20.4 \\
\hline Malawi & 34 & $1,000,000$ & 2.29 & 66 & 84 & 51 & 91 & 4.4 & 18.7 & 59.2 \\
\hline Senegal & 36 & 41,000 & 0.08 & 52 & 55 & 47 & 75 & 5.0 & 25.6 & 23.3 \\
\hline $\begin{array}{l}\text { Sierra } \\
\text { Leone }\end{array}$ & 107 & 67,000 & - & 26 & 87 & 76 & 54 & 4.9 & 25.0 & 16.6 \\
\hline Tanzania & 32 & $1,400,000$ & 1.19 & 62 & 84 & 51 & 63 & 5.2 & 22.1 & 38.4 \\
\hline Togo & 37 & 100,000 & 0.59 & 51 & 86 & 57 & 73 & 4.8 & 33.6 & 19.9 \\
\hline Uganda & 46 & $1,400,000$ & 1.50 & 67 & $>95$ & 48 & 57 & 6.2 & 34.3 & 30.0 \\
\hline Zimbabwe & 94 & $1,300,000$ & 3.03 & 75 & 93 & 76 & 77 & 4.0 & 10.4 & 66.8 \\
\hline
\end{tabular}

- indicates no data available. DRC Democratic Republic of Congo. ANC4+: Coverage of at least four antenatal care visits. ART:

CPR Contraceptive prevalence rate. TFR Total fertility rate. PMTCT Antiretroviral therapy coverage for the prevention of mother-to-child HIV transmission

a Source: World Health Organization Global Health Expenditure Database for 2015

b Source: UNAIDS estimates for 2016

' Source: most recent Demographic and Health Surveys or Multiple Indicator Cluster Survey

d Source: United Nations, Department of Economic and Social Affairs, Population Division (2017). World Contraceptive Use 2017 (POP/DB/CP/Rev2017)

\section{Measures}

The study outcome was the availability of on-site integrated FP services at the facility level, which was based on six 'structural' and one 'process of care' inputs. 'Structure' refers to characteristics of the health system in which care is being delivered, while 'process of care' describes the care delivered to patients [28]. In line with World Health Organization definition of FP readiness, the structural inputs examined were guidelines on FP, blood pressure apparatus, oral contraceptive pills, injectables, condoms, and trained staff (at least one staff member received training in FP in the previous 1-3 years) [29]. The 'process of care' input was the routine provision of FP counselling to HIV/AIDS clients as reported by the facility-in-charge.

Facilities with all the structural and process of care inputs were classified as having onsite integrated FP services; those that did not have one or more inputs were classified as not having onsite integrated FP services. This classification was selected based on the data available in both the SPA and SARA, and did not include other aspects related to the provision of integrated services, such as quality of counselling, patient satisfaction, and provider competence. While the SPAs include other data collections tools (client-provider observations, client exit interviews and health worker interviews) that might reflect a broader range of processes of care, the analysis was limited to the selected inputs to allow the inclusion of several countries with a recent SARA $(n=7)$.

The analysis was restricted to health facilities offering 'HIV care and support' services defined as any service directed towards improving the life of a person living with
HIV, including treatment of opportunistic infections, provision of palliative care and nutritional rehabilitation. Facilities offering HIV care and support services may offer other HIV services and ancillary health services, which may influence the availability of onsite integrated FP services. Therefore, we examined facility-level measures of the availability of other HIV services (PMTCT, HIV testing and counselling, and HIV/AIDS antiretroviral prescription and client management) and ancillary services (antenatal care, child immunizations, obstetric and newborn care, diagnosis and treatment for sexually transmitted infections, and basic surgical services). Other facility-level characteristics assessed included type of health facility (tertiary versus secondary and primary level), location (urban versus rural), and managing authority (public versus private).

\section{Analysis}

Using descriptive statistics, we summarized the availability of FP services, and structural and process of care inputs across the 10 sub-Saharan African countries. Bivariate and multivariate logistic regression analyses were conducted with availability of onsite integrated FP services as the outcome; backwards stepwise logistic regression was used to determine the facility-level factors associated with the outcome. Analyses included fixed effects for each country. To account for the dependence between facilities within the same country, we used generalized estimating equations to obtain robust standard errors [30]. Associations were presented as odds ratios (OR) with 95\% confidence intervals (95\% CI), and $p<0.05$ was considered statistically significant. Multicollinearity 
among independent variables was assessed using variance inflation factors (VIF). All statistical analyses were appropriately weighted for sample design and performed using STATA 14.2 (College Station, Texas).

\section{Results}

Of the 6209 sampled health facilities, 3161 (51\%) offered HIV care and support services and were included in our analytical sample (Table 2). FP services were offered at most HIV care and support sites (across country median: 93\%). As an enabling environment is critical to the provision of integrated FP services, we assessed the availability of structural inputs in HIV care and support sites. Whereas blood pressure equipment was widely available (median: 92\%), guidelines on FP and staff trained in FP were less available (median: 65 and 50\% respectively). By and large, injectable contraceptives, oral contraceptive pills, and male condoms were largely available (median: 89, 83 and 82\% respectively). However, there was a relatively lower supply of implants and intrauterine devices (IUDs), which offer long-acting reversible contraception (median: 62 and 41\% respectively; Fig. 1). The availability of female condoms and emergency contraception varied widely across countries (range: 10$97 \%$ and $10-82 \%$, respectively). Across countries, a median of $95 \%$ of the HIV care and support sites had one or more contraceptive methods in stock (range: 85$100 \%$ ), and $80 \%$ had three or more contraceptive methods in stock (range: 57-97\%, Fig. 1). Most HIV care and support sites reported routinely providing FP counselling to HIV/AIDS clients - an indicator of the process of care (median: 94\%).

Based on the availability of structural inputs and process of care indicators, the onsite availability of integrated FP services varied between 10 and 61\%, with a median of $29 \%$ across all countries (Table 2). Notably, countries with similar onsite availability of integrated FP services showed varying availability of HIV care and support services. Whereas about $26 \%$ of HIV care and support sites in DRC and Uganda were classified as having onsite integrated FP services available, only $8 \%$ of all sampled facilities offered HIV care and support services in DRC compared to $54 \%$ in Uganda.

In the bivariate analyses, the availability of integrated FP services at HIV care and support sites was associated with several facility-level characteristics (Table 3). Except for HIV testing and counselling and diagnosis and treatment of sexually transmitted infection, offering another HIV or ancillary health services was independently associated with higher odds of having integrated FP services. In the multivariate analyses, public HIV care and support sites had higher odds of having onsite integrated FP services available compared with private sites (aOR 1.95, 95\% CI: 1.12-3.40; Table 3). Tertiary level sites had higher odds of having integrated FP services available than secondary and primary level sites, though this was only marginally statistically significant (aOR 1.49; 95\% CI 1.00-2.22). There was no association between the availability of onsite integrated FP services and rural-urban location (aOR 0.95, 95\% CI 0.59-1.54). The odds of having integrated FP services available was higher among HIV care and support sites that provided services for PMTCT (aOR: 3.66, 95\% CI 1.10-12.17), antenatal care (aOR: $2.95,95 \%$ CI 1.22-7.14) and basic surgery (aOR: $1.88,95 \%$ CI 1.03-3.43), compared to sites that did not provide these services. With the exception of Togo and Sierra Leone, the odds of having integrated FP services available were significantly higher in Burkina Faso than the remaining countries.

\section{Discussion}

Women living with HIV face disproportionately higher rates of unintended pregnancies and the integration of FP and HIV services is a strategy to meet FP needs, reduce the risk of unintended pregnancies, and prevent mother-to-child HIV transmission. This study evaluated the availability of integrated FP services and associated factors in HIV care and support sites across 10 sub-Saharan African countries between 2012 and 2015. Whereas the majority (93\%) of HIV care and support sites reported offering FP services in the same location, only $29 \%$ of these sites were classified as having onsite integrated FP services available based on the availability of structural and process of care inputs. FP commodities and blood pressure equipment were widely available; however, the availability of guidelines on FP and trained staff were limited. Of note, there were no rural-urban differences in the onsite availability integrated FP services (aOR 0.95, 95\% CI 0.59-1.54). This finding is indicative that global efforts to ensure the widespread availability of such services may be gaining traction in both rural and urban settings in sub-Saharan Africa [31]. That said, the lack of trained staff is concerning given the indicator for trained staff, defined as at least one staff member had been trained in any aspect of FP in the previous 1-3 years, represents a minimum requirement. Given the chronic shortage of all cadres of health personnel in the sub-Saharan Africa region and the current rhetoric of double-duty actions, efforts for dual training and supervision of providers should be considered $[32,33]$. Barriers to the provision of integrated FP services specifically training and supervision must be addressed if the comprehensive needs of people living with HIV are to be met.

We documented variation across countries in the availability of integrated FP services in HIV care and support sites. Differences in the burden of HIV, FP needs and other health system factors may drive the heterogeneity in 


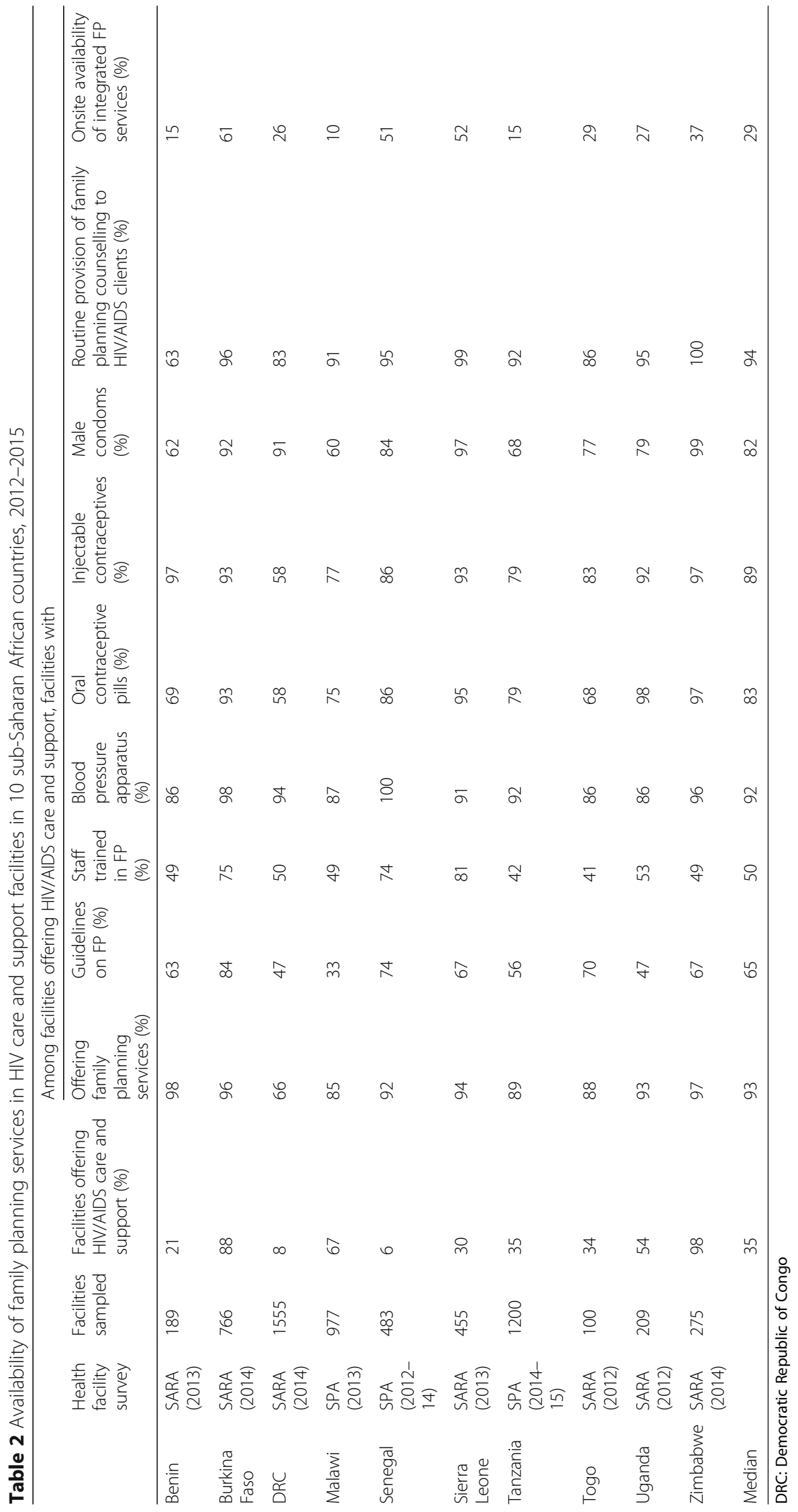




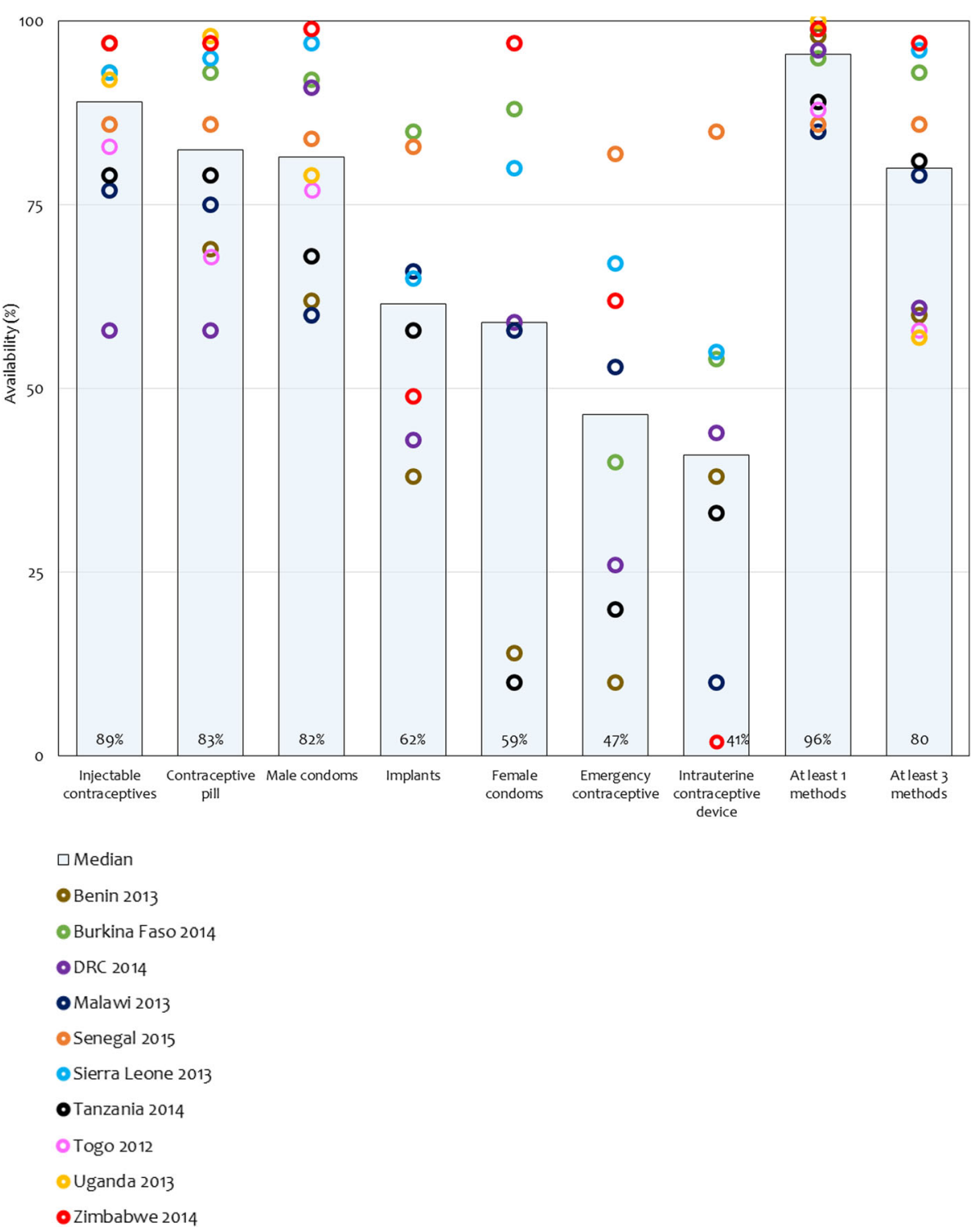

Fig. 1 Contraceptive methods available at HIV care and support sites in 10 sub-Saharan African countries

the availability of HIV/FP integration. Furthermore, the strengthens and limitations of one model integration over another in different contexts has not been fully explored [34].

Our findings also suggest that HIV care and support sites offering other HIV or ancillary services, specifically PMTCT, ANC and basic surgery services were more likely to have integrated FP services available. Notably, offering PMTCT services was associated with a 3.6-fold increase in the likelihood of onsite integrated FP services, suggesting that HIV care and support sites already equipped with PMTCT units were also inclined to offer integrated FP, or vice versa. Several studies have also documented the positive spillover effect of HIV programs on broader health systems, including the provision and quality of ANC, obstetric care, and child immunization services [35-37]. For instance, one study of health facilities in Kenya found that the presence of PMTCT programs was associated with increased quality of prenatal and postnatal care, specifically the availability of structural inputs [37]. Together, these studies and our findings suggest that investments in supplies, equipment, diagnostics, human resources, medicines and commodities to support the provision of PMTCT services may have substantial indirect benefits on health systems.

We also found that onsite integrated FP services were more available in HIV care and support sites that were government operated and provided tertiary level care. These findings are consistent with studies that have documented supply side deficiencies in the provision of 
Table 3 Univariate and Multivariate analyses of factors associated with onsite availability of integrated family planning services in HIV care and support sites in 10 sub-Saharan African countries, 2012-2015

\begin{tabular}{|c|c|c|c|c|}
\hline \multirow[b]{2}{*}{ Facility-level characteristic } & \multicolumn{2}{|c|}{$\underline{\text { Univariate }}$} & \multicolumn{2}{|c|}{ Multivariate } \\
\hline & OR & $95 \% \mathrm{Cl}$ & $\mathrm{aOR}$ & $95 \% \mathrm{Cl}$ \\
\hline Urban & 1.32 & $0.92-1.90$ & 0.95 & $0.59-1.54$ \\
\hline Tertiary level & 1.28 & $0.95-1.73$ & 1.49 & $1.00-2.22$ \\
\hline Public & 2.43 & $1.55-3.83$ & 1.95 & $1.12-3.40$ \\
\hline \multicolumn{5}{|l|}{ Offers other HIV ancillary health services } \\
\hline PMTCT services & 10.36 & $4.22-25.44$ & 3.66 & $1.10-12.17$ \\
\hline Antenatal care & 9.20 & $5.66-14.96$ & 2.95 & $1.22-7.14$ \\
\hline Basic surgery & 2.37 & $1.52-3.69$ & 1.88 & $1.03-3.43$ \\
\hline Obstetric and newborn care & 6.89 & $3.03-15.65$ & - & \\
\hline Child immunization & 3.47 & $2.34-5.14$ & - & \\
\hline HIV testing and counselling & 3.36 & $0.73-15.47$ & - & \\
\hline HIV/AIDS antiretroviral prescriptions & 2.73 & $1.60-4.63$ & - & \\
\hline Sexually transmitted infections & 0.44 & $0.10-1.86$ & - & \\
\hline \multicolumn{5}{|l|}{ Country } \\
\hline Burkina Faso & - & & Reference & \\
\hline Benin & - & & 0.13 & $0.05-0.37$ \\
\hline Democratic Republic of Congo & - & & 0.23 & $0.14-0.40$ \\
\hline Malawi & - & & 0.09 & $0.06-0.12$ \\
\hline Senegal & - & & 0.53 & $0.27-1.05$ \\
\hline Sierra Leone & - & & 0.75 & $0.50-1.13$ \\
\hline Tanzania & - & & 0.11 & $0.08-0.16$ \\
\hline Togo & - & & 0.42 & $0.18-1.03$ \\
\hline Uganda & - & & 0.35 & $0.19-0.64$ \\
\hline Zimbabwe & - & & 0.59 & $0.37-0.95$ \\
\hline
\end{tabular}

Cl confidence interval, $O R$ odds ratio, $a O R$ adjusted odds ratio

essential health services across sub-Saharan African countries, particularly lower level facilities [36, 38, 39]. In light of efforts to decentralize HIV programs to lower level facilities to ensure improved access and support rapid scale up [40, 41], our results underscore the need for further investments in lower level facilities where a substantial number of patients are expected to receive HIV care and FP in the near future.

There are several limitations worth noting. First, the analysis was based on a secondary analysis of data collected through health facility surveys. Health facility surveys such as the SPA and SARA provide nationally representative information on the state of the health system at one moment in time, and the surveys used reflect service provision between 2012 and 2015. As some HIV care and support sites may provide integrated FP services to few or many HIV clients, without adjustment for care-seeking patterns and health facility caseloads, our data cannot identify the proportion of HIV clients receiving integrated FP services in HIV care and support settings, nor specify the actual content and quality of care received by these clients. The availability of structural inputs and processes of care is a requirement but not a guarantee of provision of integrated FP services. Nevertheless, these findings are still useful in characterizing the environment in which integrated FP and HIV services are being provided and are relevant for national-level policy and program planning.

Second, the present analysis was restricted to assessing the availability of FP services in the same site to HIV-infected women in HIV care and support sites. Due to the nature of the data, it is unclear whether the FP services were provided by the same health provider, or another health provider in the same facility through formal or informal referral. The study did not consider other models of service delivery (e.g. referral based approaches) or the availability of other reproductive services (e.g. those targeted for men and adolescent boys). Data available in the SPA and SARA do not permit the assessment of all integrated service delivery mechanisms operating in HIV care and support sites or other HIV programs like HIV counselling and testing, PMTCT and 
ART. However, other HIV programs are likely to face parallel challenges in the delivery of integrated FP and HIV services. Further research is needed to better understand the broader spectrum of activities in which HIV care and support sites are engaged to meet the FP needs of both male and female HIV clients.

Third, the definition of availability of onsite integrated FP services was based on the availability of structural inputs and process of care. While the availability of structural inputs was based on direct observation and verification, the indicator for process of care - routine provision of FP counselling to HIV clients was based on report by facility staff, which is prone to misreporting. Also, the definition only considered one indicator of the process of care and may be too crude a measure to represent all dimensions of integrated FP service delivery. Several other indicators have been proposed to track the integration between FP and HIV services at the health facility level with more depth and breadth [42-44]. In addition to service readiness, these evaluation frameworks also consider demand for services, provider training, knowledge and competence, client reports of service provision, and monitoring and evaluation. The use of standard indicators and data collected from client exit interviews and client observations would facilitate the monitoring and evaluation of integrated service delivery and quality. Nevertheless, the definition used in the present study for onsite availability of integrated services reflects the minimum level of service readiness required to provide integrated FP services, which makes it the more concerning that few health facilities met these requirements.

Despite these limitations, our study included health facilities representing a diverse array of settings and contexts, including private, lower level and rural health facilities in 10 sub-Saharan African countries. The included countries represent varying trends in HIV transmission and sexual and reproductive health needs, increasing the generalizability our findings. Together, the 10 countries represent about $23 \%$ of the people living with HIV in sub-Saharan Africa.

\section{Conclusions}

Our findings demonstrate that the availability of on-site integrated HIV care and FP services in sub-Saharan Africa is low, despite the provision of FP services being one of the four pillars of the global effort to prevent mother-to-child transmission. There are deficits in the components necessary to provide integrated services, particularly the training of providers. Our findings call for the expansion of integrated FP services to privately owned facilities, lower level facilities and facilities lacking a range of other HIV and ancillary services. The results of this study provide evidence to inform Ministries of Health and other stakeholders in the region on efforts to implement integrated FP and HIV services at scale.

A French translation of this article has been included as Additional file 1.

A Portuguese translation of the abstract has been included as Additional file 2.

\section{Additional files}

Additional file 1: Translation of this article into French. (PDF $674 \mathrm{~kb}$ )

Additional file 2: Translation of the abstract of this article into

Portuguese. (PDF $176 \mathrm{~kb}$ )

\section{Abbreviations}

AIDS: Acquired immunodeficiency syndrome; ANC: Antenatal care; aOR: Adjusted odds ratio; ART: Antiretroviral therapy; Cl: Confidence interval; DHS: Demographic and Health Surveys; DRC: Democratic Republic of Congo; FP: Family planning; HIV: Human immunodeficiency virus; IUD: Intrauterine device; OR: Odds ratio; PMTCT: Prevention of mother-to-child HIV transmission; SARA: Service Availability and Readiness Assessment; SPA: Service Provision Assessment

\section{Acknowledgements}

None.

\section{Funding}

The journal supplement is made possible by the generous support of the American People through the United States Agency for International Development (USAID) in partnership with United Nations Population Fund (UNFPA) and The Joint United Nations Program on HIV/AIDS (UNAIDS). The views expressed in this publication are solely the opinions of the authors and do not necessarily reflect the official policies of the USAID, UNFPA or UNAIDS, nor does mention of the department or agency names imply endorsement by the U.S. Government, UNFPA or UNAIDS.

Availability of data and materials

All data used in this manuscript can be requested at: https://dhsprogram. com/Data/ and http://www.who.int/healthinfo/systems/sara_introduction/en/

\section{About this supplement}

This article has been published as part of Reproductive Health, Volume 16 Supplement 1, 2019: Effective Integration of Sexual Reproductive Health and HIV Prevention, Treatment, and Care Services across sub-Saharan Africa: Where is the evidence for program implementation? The full contents of the supplement, published as a joint collaboration between Reproductive Health and BMC Public Health, are available online at https://reproductive-health-journal.biomedcentral. com/articles/supplements/volume-16-supplement-1 and https://bmcpublichealth. biomedcentral.com/articles/supplements/volume-19-supplement-1.

\section{Authors' contributions}

MK, AL and KS jointly conceived the study. MK conducted the analysis and wrote the first draft of the paper. AL and KS provided critical review and comments. All authors read and approved the final manuscript.

Ethics approval and consent to participate Not applicable.

\section{Consent for publication}

Not applicable.

\section{Competing interests}

The authors declare that they have no competing interests.

\section{Publisher's Note}

Springer Nature remains neutral with regard to jurisdictional claims in published maps and institutional affiliations. 


\section{Author details}

'Department of International Health, Johns Hopkins Bloomberg School of Public Health, 615 N. Wolfe Street, Baltimore, MD, USA. ²Department of Public and Environmental Wellness, School of Health Sciences, Oakland University, Rochester, MI, USA. ${ }^{3}$ Department of Population, Family, and Reproductive Health, School of Public Health, College of Health Sciences, University of Ghana, Accra, Ghana.

\section{Published: 29 May 2019}

\section{References}

1. Joint United Nations Programme on HIV/AIDS. UNAIDS DATA 2017. 2017.

2. De Cock KM, Fowler MG, Mercier E, de Vincenzi I, Saba J, Hoff E, et al. Prevention of mother-to-child HIV transmission in resource-poor countries: translating research into policy and practice. JAMA. 2000;283(9):1175-82.

3. UNAIDS, UNICEF, World Health Organization. Global HIV/AIDS response: epidemic update and health sector progress towards universal access: progress report 2011: World Health Organization; 2011.

4. Schwartz SR, Rees H, Mehta S, Venter WDF, Taha TE, Black V. High incidence of unplanned pregnancy after antiretroviral therapy initiation: findings from a prospective cohort study in South Africa. PLoS One. 2012;7(4):e36039.

5. Adair T. Unmet need for contraception among HIV-positive women in Lesotho and implications for mother-to-child transmission. J Biosoc Sci. 2009;41(2):269-78.

6. Warren CE, Abuya T, Askew I. Family planning practices and pregnancy intentions among HIV-positive and HIV-negative postpartum women in Swaziland: a cross sectional survey. BMC Pregnancy Childbirth. 2013;13:150.

7. McCoy SI, Buzdugan R, Ralph LJ, Mushavi A, Mahomva A, Hakobyan A, et al. Unmet need for family planning, contraceptive failure, and unintended pregnancy among HIV-infected and HIV-uninfected women in Zimbabwe. PLoS One. 2014:9(8):e105320.

8. Laar AK, Taylor AE, Akasoe BA. HIV-seropositivity is not important in childbearing decision-making among HIV-positive Ghanaian women receiving antiretroviral therapy. AIDS Care. 2015;27(7):870-5.

9. World Health Organization. The Glion call to action on family planning and HIV/AIDS in women and children. Geneva: WHO; 2004.

10. World Health Organization. World Malaria Report 2014. 2014.

11. Tsui AO, McDonald-Mosley R, Burke AE. Family planning and the burden of unintended pregnancies. Epidemiol Rev. 2010;32(1):152-74.

12. Reynolds HW, Janowitz B, Homan R, Johnson L. The value of contraception to prevent perinatal HIV transmission. Sex Transm Dis. 2006 Jun;33(6):350-6.

13. Stover J, Fuchs N, Halperin D, Gibbons A, Gillespie D. United States Agency for International Development (USAID). Adding family planning to PMTCT sites increases the benefits of PMTCT. Washington, DC: USAID; 2003.

14. Grossman D, Onono M, Newmann SJ, Blat C, Bukusi EA, Shade SB, et al. Integration of family planning services into HIV care and treatment in Kenya: a cluster-randomized trial. AIDS. 2013;27(Suppl 1):S77-85.

15. Church K, Mayhew SH. Integration of STI and HIV prevention, care, and treatment into family planning services: a review of the literature. Stud Fam Plan. 2009;40(3):171-86.

16. Shade SB, Kevany S, Onono M, Ochieng G, Steinfeld RL, Grossman D, et al. Cost, cost-efficiency and cost-effectiveness of integrated family planning and HIV services. AIDS. 2013;27(Suppl 1):S87-92.

17. Haberlen SA, Narasimhan M, Beres LK, Kennedy CE. Integration of family planning services into HIV care and treatment services: a systematic review. Stud Fam Plan. 2017:48(2):153-77.

18. Hope R, Kendall T, Langer A, Bärnighausen T. Health systems integration of sexual and reproductive health and HIV Services in sub-Saharan Africa: A Scoping Study. J. Acquir. Immune Defic. Syndr. 2014;67:S259-70.

19. World Health Organization. Integrating sexual and reproductive health-care services: policy brief. Geneva: WHO; 2006.

20. Adamchak S, Janowitz B, Liku J, Munyambanza E, Grey T, Keyes E. Study of family planning and HIV integrated services in five countries. Fam Heal Int Res Triangle Park NC, USA. 2010;

21. Johnson K, Varallyay I, Ametepi P. Integration of HIV and family planning health services in sub-Saharan Africa: a review of the literature current recommendations and evidence from the service provision assessment health facility surveys; 2012.

22. Kosgei RJ, Lubano KM, Shen C, Wools-Kaloustian KK, Musick BS, Siika AM, et al. Impact of integrated family planning and HIV care services on contraceptive use and pregnancy outcomes: a retrospective cohort study. J Acquir Immune Defic Syndr. 2011;58(5):e121-6.
23. Phiri S, Feldacker C, Chaweza T, Mlundira L, Tweya H, Speight C, et al. Integrating reproductive health services into HIV care: strategies for successful implementation in a low-resource HIV clinic in Lilongwe, Malawi. BMJ Sex Reprod Heal. 2016:42(1):17-23.

24. Haddad LB, Feldacker C, Jamieson DJ, Tweya H, Cwiak C, Bryant AG, et al. Medical eligibility, contraceptive choice, and intrauterine device acceptance among HIV-infected women receiving antiretroviral therapy in Lilongwe, Malawi. Int J Gynaecol Obstet. 2014;126(3):213-6.

25. Haddad LB, Feldacker C, Jamieson DJ, Tweya H, Cwiak C, Chaweza T, et al. Pregnancy prevention and condom use practices among HIV-infected women on antiretroviral therapy seeking family planning in Lilongwe, Malawi. PLoS One. 2015;10(3):1-14.

26. The DHS Program - Service Provision Assessments (SPA) [Internet]. [cited 2016 Oct 31]. Available from: http://dhsprogram.com/What-We-Do/SurveyTypes/SPA.cfm.

27. $\mathrm{WHO} \mid$ Service availability and readiness assessment (SARA) [Internet]. [cited 2017 Oct 31]. Available from: http://www.who.int/healthinfo/systems/sara_ introduction/en/.

28. Donabedian A. The quality of care: how can it be assessed? Jama. 1988; 260(12):1743-8.

29. World Health Organization. Service availability and readiness assessment (SARA): an annual monitoring system for service delivery: reference manual. 2013;

30. Lipsitz SR, Laird NM, Harrington DP. Generalized estimating equations for correlated binary data: using the odds ratio as a measure of association. Biometrika. 1991;78(1):153-60.

31. Bongaarts J, Cleland J, Townsend JW, Bertrand JT, Das GM. Family planning programs for the 21st century. New York: Popul Counc; 2012.

32. Bharat S, Mahendra VS. Meeting the sexual and reproductive health needs of people living with HIV: challenges for health care providers. Reprod Health Matters. 2007;15(29 Suppl):93-112.

33. Kane R, Wellings K. Staff training in integrated sexual health services. Sex Transm Infect. 2003;79(5):354-6.

34. Mayhew SH, Hopkins J, Warren CE. Building integrated health systems: lessons from HIV, sexual and reproductive health integration. Health Policy Plan. 2017;32(suppl_4):iv1-5.

35. Ekouevi DK, Stringer E, Coetzee D, Tih P, Creek T, Stinson K, et al. Health facility characteristics and their relationship to coverage of PMTCT of HIV services across four African countries: the PEARL study. PLoS One. 2012;7(1):1-7.

36. Kruk ME, Leslie HH, Verguet S, Mbaruku GM, Adanu RMK, Langer A. Quality of basic maternal care functions in health facilities of five African countries: an analysis of national health system surveys. Lancet Glob Heal. 2016;16:1-11.

37. Kruk ME, Jakubowski A, Rabkin M, Kimanga DO, Kundu F, Lim T, et al. Association between HIV programs and quality of maternal health inputs and processes in Kenya. Am J Public Health. 2015;105(S2):S207-10.

38. Kanyangarara M, Walker N, Munos M. Quality of antenatal care service provision in health facilities across sub-Saharan Africa: evidence from nationally representative health facility assessments. J Glob Health. 2017;7(2):021101.

39. Church K, Machiyama K, Todd J, Njamwea B, Mwangome M, Hosegood V, et al. Identifying gaps in HIV service delivery across the diagnosis-totreatment cascade: findings from health facility surveys in six sub-Saharan countries. J Int AIDS Soc. 2017;20(1):21188.

40. Fayorsey RN, Saito S, Carter RJ, Gusmao E, Frederix K, Koech-Keter E, et al. Decentralization of pediatric HIV care and treatment in five sub-Saharan African countries. JAIDS J Acquir Immune Defic Syndr. 2013;62(5):e124-30.

41. Scanlon ML, Vreeman RC. Current strategies for improving access and adherence to antiretroviral therapies in resource-limited settings. HIV/AIDS (Auckland, NZ). 2013;5:1-17.

42. Inter-agency Working Group on SRH and HIV Linkages. SRH and HIV Linkages Compendium: Indicators and related assessment tools. London: IPPF, UNFPA, WHO; 2014.

43. Freyder M, Craig L, Kaji A. Monitoring the Integration of Family Planning and HIV Services: A Manual to Support the Use of Indicators to Measure Progress toward PEPFAR's 90-90-90 Targets and Protect Women's Reproductive Rights. North Carolina: MEASURE Evaluation; 2016.

44. Adamchak SE, Okello FO, Kabore I. Developing a system to monitor family planning and HIV service integration: results from a pilot test of indicators. J Fam Plan Reprod Heal care. 2016;42(1):24-9. 